\title{
QUALIDADE FISIOLÓGICA DE SEMENTES DE SORGO (Sorghum bicolor (L.) Moench.) DANIFICADAS APÓS ARMAZENAMENTO ${ }^{1}$
}

\author{
DEA ALECIA M. NETTO ${ }^{2}$, CLEVERSON S. BORBA ${ }^{2,3}$, ANTOONIO CARLOS DE OLIVEIRA ${ }^{2}$, \\ JOÄO TITO DE AZEVEDO'², RAMIRO V. ANDRADE ${ }^{2}$ e CLAUDINEI ANDREOLI
}

\begin{abstract}
RESUMO - Dez lotes de sementes de sorgo cultivar BR 303, com diferentes percentagens de danos mecânicos, foram analisados com o objetivo de se determinar o efeito de danos mecânicos sobre a qualidade fisiológica após armazenamento. Os níveis de dano mecânico foram determinados pelo teste de verde rápido e a qualidade fisiológica pelo teste de germinação, envelhecimento acelerado, teste de frio, índice de velocidade de emergência e população inicial de plântulas. $O$ efeito prejudicial dos danos mecânicos sobre a qualidade fisiológica das sementes de sorgo não tratadas com fungicidas e armazenadas por seis meses pôde ser detectada pelos vários testes aplicados. Independentemente do grau de dano mecânico, não houve diferença na qualidade das sementes armazenadas em câmara fria e tratadas com fungicida em relação àquelas armazenadas em ambiente.
\end{abstract}

Termos para indexação: germinação, vigor, dano estratificado, armazenamento, thiram.

\section{SORGHUM (Sorghum bicolor (L.) Moench.) SEED DAMAGED PHYSIOLOGICAL QUALITY AFTER STORAGE}

\begin{abstract}
Ten seed lots of sorghum cultivar BR 303, with different mechanical damage levels were evaluated by germination and vigor test after storage. Mechanical damage was detected by fast green test, and the seed quality was evaluated by acelerating ageing, cold test, rate of germination and stand establishment. Significant decrease on germination and vigor results were detected. The hazard effect of mechanical damages on physiological quality of undressed sorghum seeds after six month storage was detected. Independently of the mechanical damage levels there was not difference in seed quality among seeds dressed with fungicide and stored seeds before storage.
\end{abstract}

Index terms: germination, vigor tests, estratified damage, thiram.

\section{INTRODUÇÃO}

O sorgo ocupa o quinto lugar entre os cereais mais importantes na produção de grãos; nos países em desenvolvimento, é economicamente importante para alimentação humana e animal, além de servir como matéria prima para vários subprodutos industrializados. Dado o grande potencial dessa cultura para várias regiões brasileiras e a falta de informação, torna-se necessária a inclusão num programa de pesquisa, de estudos da qualidade fisiológica e conservação de sementes a curto, médio e longo prazos.

Um dos fatores, mais importantes, que afeta a qualidade das sementes é o dano mecânico podendo ocorrer durante a

\footnotetext{
${ }^{1}$ Aceito para publicação em 19.11.97.

${ }^{2}$ Pesquisadores do CNPMS/EMBRAPA, Cx. Postal 151-285, CEP 35701970. Sete Lagoas - MG.

${ }^{3}$ Bolsista do CNPq.
}

colheita, o beneficiamento ou o transporte das sementes. Além dos danos visíveis representados por rachaduras, quebras e sementes fragmentadas, sementes severamente danificadas podem apresentar redução de qualidade fisiológica, imediatamente após o dano, ou podem ocorrer efeitos latentes, os quais se manifestam após períodos variáveis de armazenamento (Popinigis, 1977). Vários trabalhos foram realizados sobre os efeitos imediatos e latentes dos danos mecânicos na qualidade fisiológica das sementes de milho, sorgo e soja (Silveira,1974; Teng, 1981; Vantoai, 1983; Garcia \& Lasa, 1991; Borba et al., 1994 e Andrade et al., 1996).

Sementes de milho com diferentes porcentagens de danos mecânicos apresentaram diferenças significativas na sua qualidade fisiológica, detectadas pelos testes de vigor (envelhecimento acelerado, teste de frio e índice de velocidade de emergência) (Gomez, 1971). Segundo esse autor, a redução na germinação pelo teste de frio foi diretamente proporcional ao aumento no grau de injúria mecânica, sendo este teste o mais eficaz para detectar o efeito dos danos após o armazenamento das sementes, ou seja, dos danos latentes. 
A perda da viabilidade e vigor de sementes de sorgo em condições variáveis de armazenamento foram estudados por Aswathaiah et al. (1989). Esses autores detectaram que não houve queda na viabilidade das sementes quando armazenadas por 87 dias em condições ambientais. Porém, quando armazenadas em condições de $60 \%$ de umidade relativa, ou mais, e $30^{\circ} \mathrm{C}$, houve decréscimo na germinação e no vigor. Concluíram que a viabilidade é sensível a mudanças do ambiente. Já Mehta \& Patel (1990) encontraram que a porcentagem de germinação e o índice de vigor diminuiram com o aumento do período de armazenamento, porém o armazenamento sob baixas temperaturas registrou os maiores valores de germinação em relação às sementes armazenadas a temperatura ambiente .

Enayathullah Shah \& Mariappan (1990) detectaram variação significativa na viabilidade de sementes de sorgo após seis e nove meses de armazenamento, sendo que, com a aplicação do fungicida Thiram, a germinação atingiu $88,66 \%$ e $73,66 \%$, respectivamente, não tendo diferença significativa para os fungicidas Vitavax, Panoctine + Panoram.

Desta forma, como há necessidade de maiores informações sobre o efeito dos danos mecânicos na qualidade de sementes de sorgo armazenadas propôs-se este trabalho.

\section{MATERIAL E MÉTODOS}

O trabalho foi conduzido no Laboratório de Tecnologia de Sementes do Centro Nacional de Pesquisa de Milho e Sorgo (CNPMS/Embrapa), Sete Lagoas-MG, no período de setembro de 1995 a março de 1996.

Dez lotes de sementes de sorgo (Sorghum bicolor (L.) Moench.), cultivar BR 303, colhidos mecanicamente e apresentando diferentes níveis de danos mecânicos, foram analisados quanto às injúrias e qualidade fisiológica. Para avaliação dos níveis de danos mecânicos foram empregadas duas repetições de 100 sementes imersas em solução de verde rápido $0,1 \%$,(Fast Green FCF) utilizada como corante das regiões das sementes com dano, por cinco minutos; em seguida, procedeuse a lavagem das sementes em água corrente e secagem à sombra, conforme o procedimento recomendado por Chowdhury (1977). As sementes foram classificadas utilizando-se lupa de aumento de seis vezes, adotando-se os seguintes critérios, baseados em Carbonell et al. (1993) com modificações:

a) semente sem dano: nenhum dano visível;

b) semente com dano pequeno: leve dano externo ou dano mecânico externo, atingindo o endosperma com profundidade sem atingir o embrião; dano mecânico externo e interno podendo apresentar rachaduras sem atingir o embrião;

c) semente com dano grande: dano mecânico com ruptura de pequena área do endosperma sem atingir o embrião; ruptura de $1 / 3$ do endosperma do lado oposto ao do embrião e/ou trinca no embrião;

d) semente com dano severo: fraturas atingindo $50 \%$ do endosperma e atingindo pequena área do embrião ou atingindo severamente 0 embrião.

Os lotes de sementes de sorgo foram armazenados, com e sem aplicação de fungicuda, em dois ambientes por seis meses, variando-se local de armazenamento. Foi estudado o efeito do fungicida Thiram + Vitavax PM de composição Carboxin 375g/ $\mathrm{kg}$ e Thiram $375 \mathrm{~g} / \mathrm{kg}$ na proporção de $200 \mathrm{~g}$ por $100 \mathrm{~kg}$ de sementes, sobre a germinação e vigor das sementes de sorgo danificadas e armazenadas. Designou-se os tratamentos por ASF, a armazenagem das sementes em galpão (condições ambientais) e sem a aplicação de fungicida; ACF, a armazenagem das sementes em galpão e com a aplicação de fungicida; CFSF, a armazenagem das sementes em câmara fria $\left(10^{\circ} \mathrm{C}\right.$ e $30 \%$ UR) e sem a aplicação de fungicida; e CFCF, a armazenagem das sementes em câmara fria e a aplicação de fungicida.

As variáveis avaliadas aos seis meses de armazenamento foram: 1) grminação: realizada em rolo de papel germitest, quatro repetições de 50 sementes, que permaneceram em germinador a $20-30^{\circ} \mathrm{C}$ (Brasil, 1992); as contagens foram feitas aos sete dias computando-se a porcentagem de plântulas normais; 2) envelhecimento acelerado: utilizou-se o método do gerbox adaptado (Marcos Filho, 1994), mantido em estufa a $42^{\circ} \mathrm{C}$ por 96 horas; após este período as sementes foram colocadas para germinar conforme descrito anteriormente; 3 ) teste de frio: adotou-se o método descrito por Cícero \& Vieira (1994); 4) índice de velocidade de emergência (IVE) e população inicial (PI) de plantas, conforme descrito em Popinigis (1977), porém para o cálculo de IVE e PI utilizou-se os resultados das contagens feitas no quinto, sétimo e nono dias após a semeadura.

Os dados foram analisados estatisticamente utilizando-se delineamento experimental inteiramente casualizado e as médias dos diferentes ambientes comparadas pelo teste de Duncan a 5\% de probabilidade. O efeito do dano mecânico nas sementes em cada ambiente foi estudado através do ajuste de equação de regressão linear.

\section{RESULTADOS E DISCUSSÃO}

Apesar dos lotes terem apresentado diferentes níveis de danos, os percentuais totais se referem, basicamente, aos danos pequenos. Por esta razão, apenas esses danos foram considerados na análise estatística. Os dez lotes apresentaram as seguintes porcentagens de dano mecânico total e danos pequenos: lote 1: $0,25 \%$ e $0 \%$; lote $2: 1,75 \%$ e $1,75 \%$; lote $3: 3,50 \%$ e $3,25 \%$; lote $4: 5 \%$ e $4,25 \%$; lote $5: 11 \%$ e $10,12 \%$; lote $6: 12,5 \%$ e $11,75 \%$; lote $7: 14,75 \%$ e $13 \%$; lote $8: 15 \%$ e $14 \%$; lote $9: 19,5 \%$ e $17 \%$; lote $10: 27,75 \%$ e $23,75 \%$, respectivamente, que se constituiram em niveis de dano. 
Os efeitos prejudiciais do dano mecânico na germinação e no vigor (envelhecimento acelerado e teste de frio) das sementes após seis meses de armazenamento nos ambientes mais contrastantes (ASF: galpão, sem fungicida; CFCF: câmara, com fungicida) podem ser observados nas Tabelas de 1 a 3 e nas Figuras de 1 a 6 . O efeito latente dos danos mecânicos, detectado na germinação de sementes de sorgo, foi mais acentuado do que o efeito imediato (Tabela 1). Observou-se maior decréscimo de germinação no ASF, onde foram oferecidas as condições de armazenamento que a maioria dos produtores utiliza e independentemente do grau de dano considerado. Não houve diferença significativa quanto aos percentuais de germinação, quando as sementes sem dano mecânico foram armazenadas nos diversos ambientes pelo teste $\mathrm{F}$ a $5 \%$ de probabilidade. Entretanto, pela Figura 1, observa-se que a germinação estimada passou de $89,2 \%$ no lote de sementes sem dano para $81,1 \%$ no ASF. No lote de sementes com $10 \%$ de dano, a germinação estimada passou de $76 \%$ para $64 \%$, e com $20 \%$ passou de $62,8 \%$ para $47 \%$. Os melhores resultados de germinação de sementes, de lotes em torno de $10 \%$ de dano, se situaram nos tratamentos $\mathrm{CFCF}, \mathrm{CFSF}$ e $\mathrm{ACF}$, respectivamente, mostrando o efeito positivo da associação da aplicação do fungicida com o armazenamento em câmara fria . A partir desse nível de dano ficou evidenciado o efeito de conservação da qualidade fisiológica das sementes em câmara fria, conforme observado nas colunas dos ambientes 3 e 4 na Tabela 1.

TABELA 1. Porcentagem média de germinação de sementes de sorgo, com diferentes niveis de danos mecânicos antes e após seis meses de armazenamento. CNPMS/Embrapa, Sete Lagoas - MG, 1996.

\begin{tabular}{cccccc}
\hline & \multicolumn{5}{c}{ Germinação (\%) } \\
\cline { 3 - 6 }$(\%)$ & $\begin{array}{c}\text { Antes do } \\
\text { armazena- } \\
\text { mento }\end{array}$ & \multicolumn{5}{c}{ Após seis meses de armazenamento } \\
\cline { 2 - 6 } & ASF & ACF & CFSF & CFCF \\
\hline 0 & $95,81 \mathrm{~A}$ & $92,00 \mathrm{~A}$ & $97,00 \mathrm{~A}$ & $94,50 \mathrm{~A}$ & $98,00 \mathrm{~A}^{*}$ \\
1,75 & $79,44 \mathrm{~A}$ & $75,00 \mathrm{AB}$ & $69,00 \mathrm{~B}$ & $77,50 \mathrm{AB}$ & $77,00 \mathrm{AB}$ \\
3,25 & $80,63 \mathrm{~A}$ & $71,00 \mathrm{~B}$ & $72,50 \mathrm{AB}$ & $70,50 \mathrm{~B}$ & $77,50 \mathrm{AB}$ \\
4,25 & $79,75 \mathrm{~A}$ & $63,00 \mathrm{C}$ & $68,50 \mathrm{BC}$ & $76,00 \mathrm{AB}$ & $70,00 \mathrm{BC}$ \\
10,12 & $76,40 \mathrm{~A}$ & $64,80 \mathrm{~B}$ & $72,50 \mathrm{~A}$ & $71,30 \mathrm{~A}$ & $71,50 \mathrm{~A}$ \\
11,75 & $79,63 \mathrm{~A}$ & $61,00 \mathrm{C}$ & $69,50 \mathrm{~B}$ & $80,50 \mathrm{~A}$ & $70,50 \mathrm{~B}$ \\
13,00 & $73,72 \mathrm{~A}$ & $58,80 \mathrm{~B}$ & $60,25 \mathrm{~B}$ & $60,50 \mathrm{~B}$ & $75,30 \mathrm{~A}$ \\
14,00 & $77,63 \mathrm{~A}$ & $65,50 \mathrm{~B}$ & $66,50 \mathrm{~B}$ & $72,00 \mathrm{AB}$ & $71,00 \mathrm{AB}$ \\
17,00 & $66,50 \mathrm{~A}$ & $52,00 \mathrm{~B}$ & $53,00 \mathrm{~B}$ & $58,00 \mathrm{~B}$ & $56,50 \mathrm{~B}$ \\
23,75 & $51,56 \mathrm{~A}$ & $37,50 \mathrm{C}$ & $34,00 \mathrm{C}$ & $42,50 \mathrm{BC}$ & $48,00 \mathrm{AB}$ \\
\hline
\end{tabular}

* Médias com a mesma letra, nas linhas, não diferem significativamente a $5 \%$ de probabilidade, pelo teste de Duncan.

ASF: Armazenamento em galpão e sementes sem fungicida;

ACF: Armazenamento em galpão e sementes com fungicida;

CFSF: Armazenamento em câmara fria e sementes sem fungicida;

CFCF: Armazenamento em câmara fria e sementes com fungicida;
TABELA 2. Porcentagem média de vigor (envelhecimento acelerado) de sementes de sorgo, com diferentes níveis de danos mecânicos antes e após seis meses de armazenamento. CNPMS/Embrapa, Sete Lagoas - MG, 1996.

\begin{tabular}{ccrccc}
\hline \multirow{2}{*}{$\begin{array}{c}\text { Dano } \\
(\%)\end{array}$} & $\begin{array}{c}\text { Antes do } \\
\text { armazena- } \\
\text { mento }\end{array}$ & \multicolumn{5}{c}{ Após seis meses de armazenamento } \\
\cline { 2 - 6 } & ASF & ACF & CFSF & CFCF \\
\hline 0 & $94,75 \mathrm{~A}$ & $71,00 \mathrm{C}$ & $93,50 \mathrm{~A}$ & $85,50 \mathrm{~B}$ & $95,00 \mathrm{~A}$ \\
1,75 & $70,13 \mathrm{~A}$ & $23,00 \mathrm{C}$ & $75,50 \mathrm{~A}$ & $45,00 \mathrm{~B}$ & $74,00 \mathrm{~A}$ \\
3,25 & $68,44 \mathrm{~B}$ & $54,00 \mathrm{C}$ & $79,00 \mathrm{~A}$ & $65,00 \mathrm{~B}$ & $72,50 \mathrm{AB}$ \\
4,25 & $71,38 \mathrm{~A}$ & $27,50 \mathrm{D}$ & $63,00 \mathrm{~B}$ & $53,00 \mathrm{C}$ & $69,50 \mathrm{AB}$ \\
10,12 & $65,50 \mathrm{~A}$ & $19,25 \mathrm{C}$ & $59,00 \mathrm{~B}$ & $50,00 \mathrm{~B}$ & $68,50 \mathrm{~A}$ \\
11,75 & $72,94 \mathrm{~A}$ & $52,00 \mathrm{~B}$ & $56,50 \mathrm{~B}$ & $43,00 \mathrm{C}$ & $70,50 \mathrm{~A}$ \\
13,00 & $66,30 \mathrm{~A}$ & $17,30 \mathrm{D}$ & $60,50 \mathrm{~B}$ & $47,80 \mathrm{C}$ & $68,50 \mathrm{~A}$ \\
14,00 & $70,81 \mathrm{~A}$ & $14,50 \mathrm{D}$ & $61,00 \mathrm{~B}$ & $47,00 \mathrm{C}$ & $69,50 \mathrm{~A}$ \\
17,00 & $55,94 \mathrm{~A}$ & $12,50 \mathrm{D}$ & $40,50 \mathrm{BC}$ & $39,00 \mathrm{C}$ & $47,00 \mathrm{~B}$ \\
23,75 & $44,44 \mathrm{~A}$ & $1,50 \mathrm{C}$ & $42,50 \mathrm{~A}$ & $12,50 \mathrm{~B}$ & $46,00 \mathrm{~A}$ \\
\hline
\end{tabular}

* Médias com a mesma letra, nas linhas, não diferem significativamente a $5 \%$ de probabilidade, pelo teste de Duncan.

TABELA 3. Porcentagem de vigor (teste de frio) em sementes de sorgo, com diferentes níveis de danos mecânicos antes e após seis meses de armazenamento. CNPMS/Embrapa, Sete Lagoas - MG, 1996.

\begin{tabular}{cccccc}
\hline & \multicolumn{5}{c}{ Germinação (\%) } \\
\cline { 2 - 6 }$(\%)$ & $\begin{array}{c}\text { Antes do } \\
\text { armazena- } \\
\text { mento }\end{array}$ & \multicolumn{4}{c}{ Após seis meses de armazenamento } \\
\cline { 3 - 6 } & ASF & ACF & CFSF & CFCF \\
\hline 0 & $90,50 \mathrm{AB}$ & $84,50 \mathrm{~B}$ & $89,50 \mathrm{AB}$ & $94,50 \mathrm{~A}$ & $97,50 \mathrm{~A}$ \\
1,75 & $73,75 \mathrm{AB}$ & $63,50 \mathrm{C}$ & $69,00 \mathrm{BC}$ & $69,00 \mathrm{BC}$ & $80,00 \mathrm{~A}$ \\
3,25 & $75,75 \mathrm{~A}$ & $67,00 \mathrm{~A}$ & $68,50 \mathrm{~A}$ & $75,50 \mathrm{~B}$ & $74,00 \mathrm{~A}$ \\
4,25 & $71,50 \mathrm{~A}$ & $58,50 \mathrm{~B}$ & $70,50 \mathrm{~A}$ & $67,50 \mathrm{~A}$ & $75,00 \mathrm{~A}$ \\
10,12 & $68,80 \mathrm{~A}$ & $59,50 \mathrm{~B}$ & $60,80 \mathrm{~B}$ & $61,80 \mathrm{~B}$ & $67,30 \mathrm{~A}$ \\
11,75 & $72,50 \mathrm{~A}$ & $56,00 \mathrm{C}$ & $59,50 \mathrm{BC}$ & $72,00 \mathrm{~A}$ & $66,50 \mathrm{AB}$ \\
13,00 & $68,50 \mathrm{~A}$ & $49,80 \mathrm{C}$ & $50,00 \mathrm{C}$ & $60,80 \mathrm{~B}$ & $68,30 \mathrm{~A}$ \\
14,00 & $72,88 \mathrm{~A}$ & $52,50 \mathrm{~B}$ & $52,50 \mathrm{~B}$ & $66,00 \mathrm{~A}$ & $65,00 \mathrm{~A}$ \\
17,00 & $58,75 \mathrm{~A}$ & $44,00 \mathrm{C}$ & $55,00 \mathrm{AB}$ & $49,00 \mathrm{BC}$ & $61,00 \mathrm{~A}$ \\
23,75 & $50,19 \mathrm{~A}$ & $28,50 \mathrm{~B}$ & $32,00 \mathrm{~B}$ & $35,00 \mathrm{~B}$ & $56,00 \mathrm{~A}$ \\
\hline
\end{tabular}

* Médias com a mesma letra, nas linhas, não diferem significativamente a $5 \%$ de probabilidade, pelo teste de Duncan.

Observa-se que as sementes, antes do armazenamento (Fig. 1) apresentaram percentuais de germinação estimada variando de $89 \%$, na ausência de dano mecânico, a $59 \%$, com $23 \%$ de dano, ou seja, $1,3 \%$ de decréscimo na germinação para cada $1 \%$ de dano. Após seis meses de armazenamento em galpão, sem tratamento com fungicida, as sementes, na ausência de danos, apresentaram germinação em torno de $81 \%$; ou seja, 


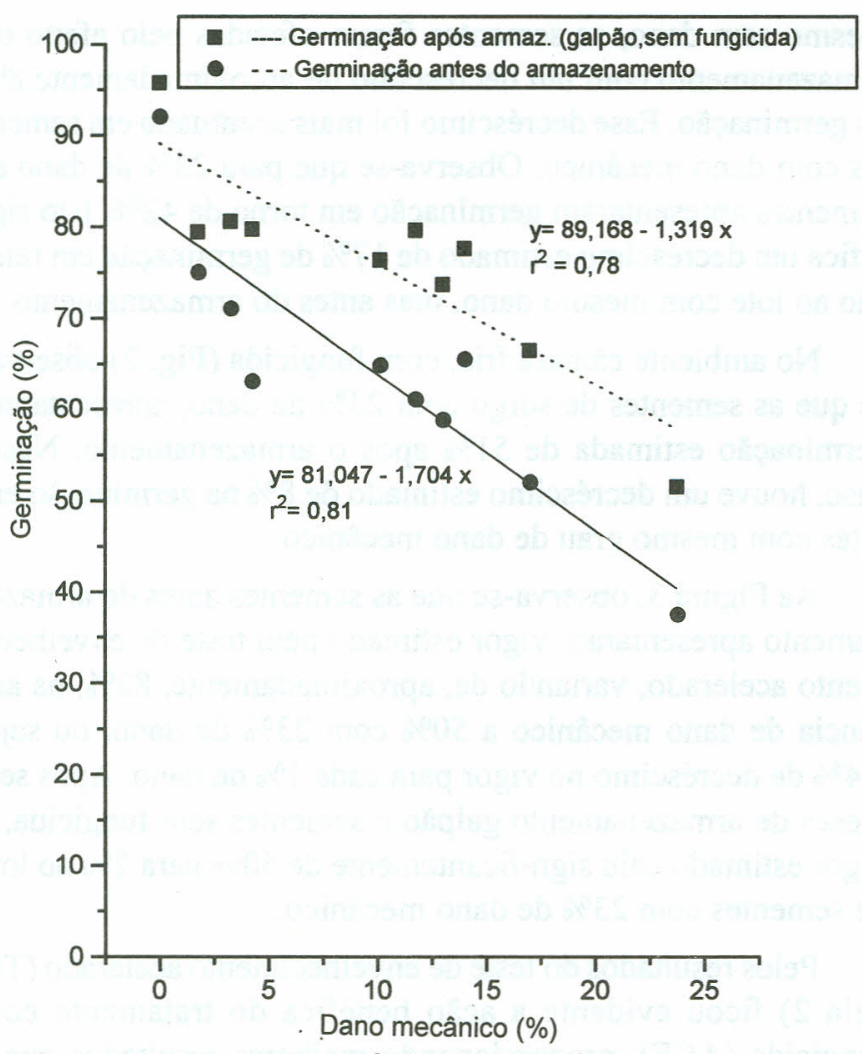

FIG. 1. Efeito do dano mecânico na germinação de sementes de sorgo, sem fungicida, antes e após armazenamento em galpão. Sete Lagoas - MG, 1996.

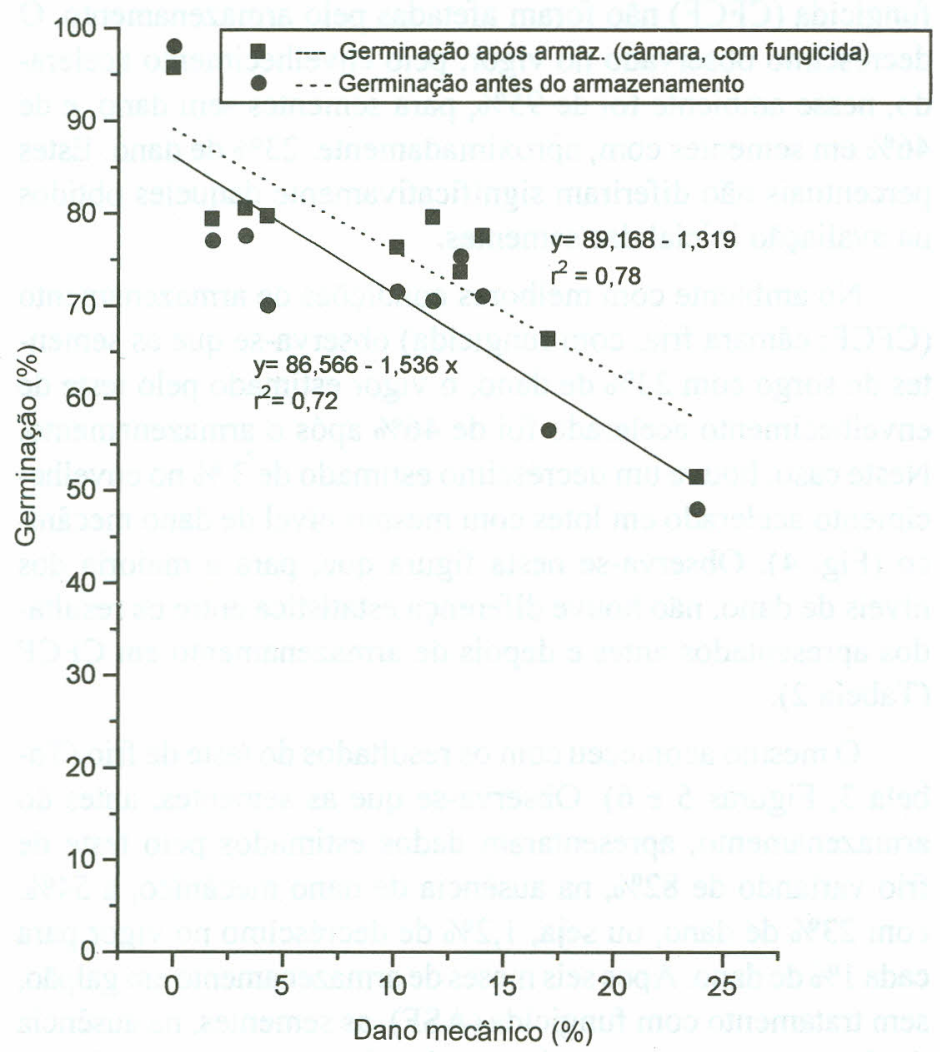

FIG. 2. Efeito do dano mecânico na germinação de sementes de sorgo, com fungicida, antes e após armazenamento em câmara fria. Sete Lagoas - MG, 1996.

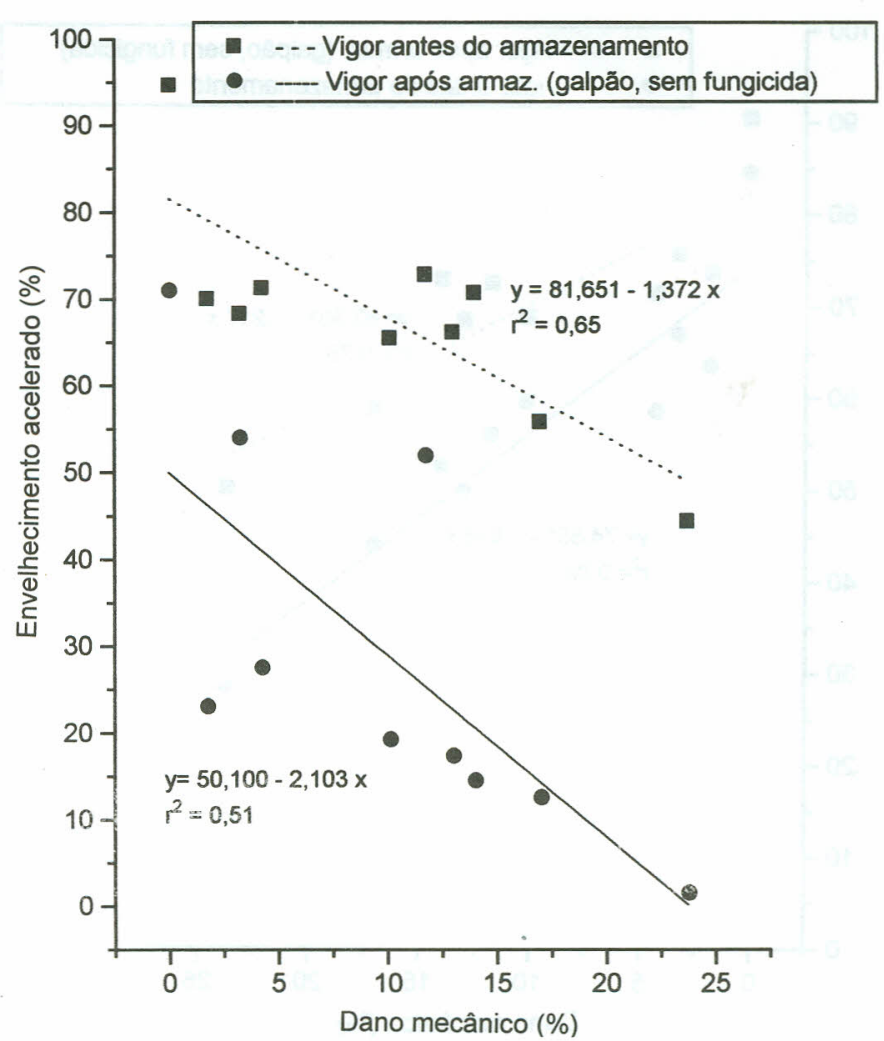

FIG. 3. Efeito do dano mecânico no vigor (envelhecimento acelerado) de sementes de sorgo, sem fungicida, após armazenamento em galpão. Sete Lagoas - MG, 1996.

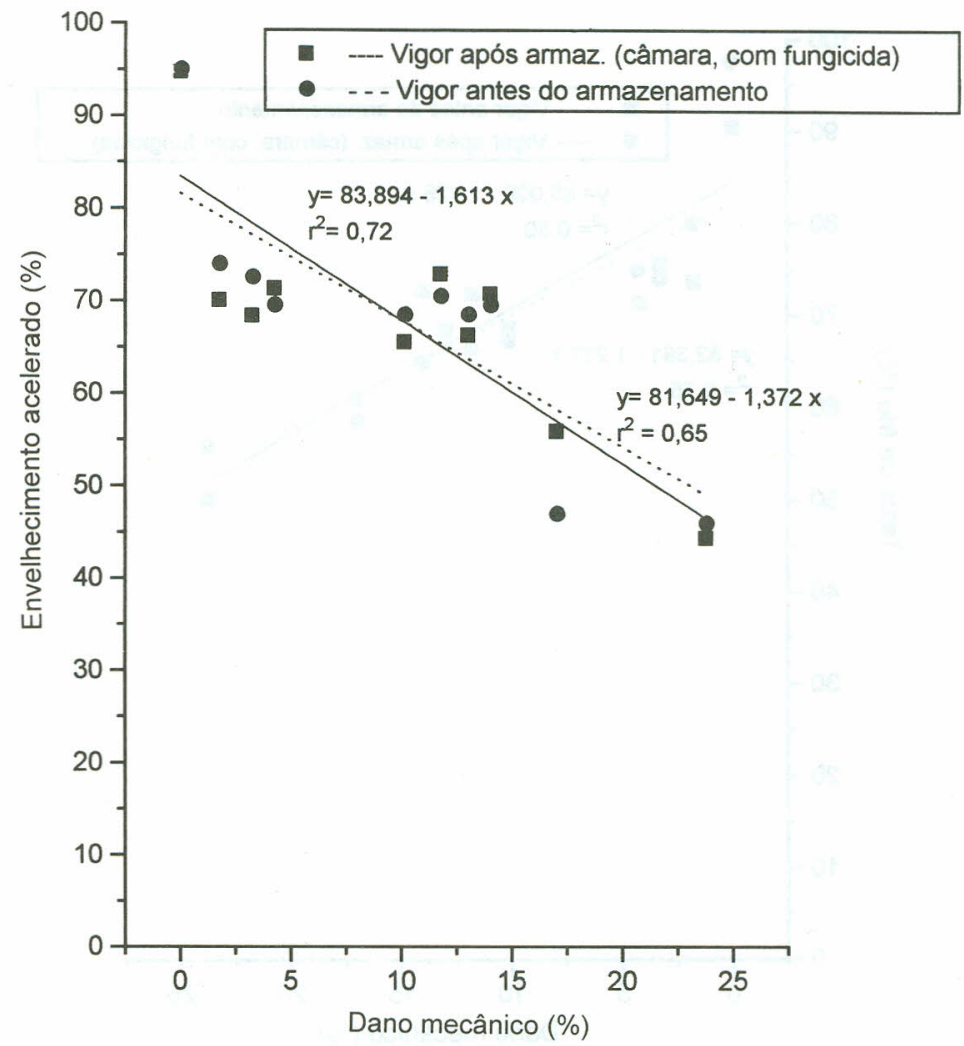

FIG. 4. Efeito do dano mecânico no vigor (envelhecimento acelerado) de sementes de sorgo, com fungicida, antes e após armaznamento em câmara fria. Sete Lagoas - MG. 1996. 


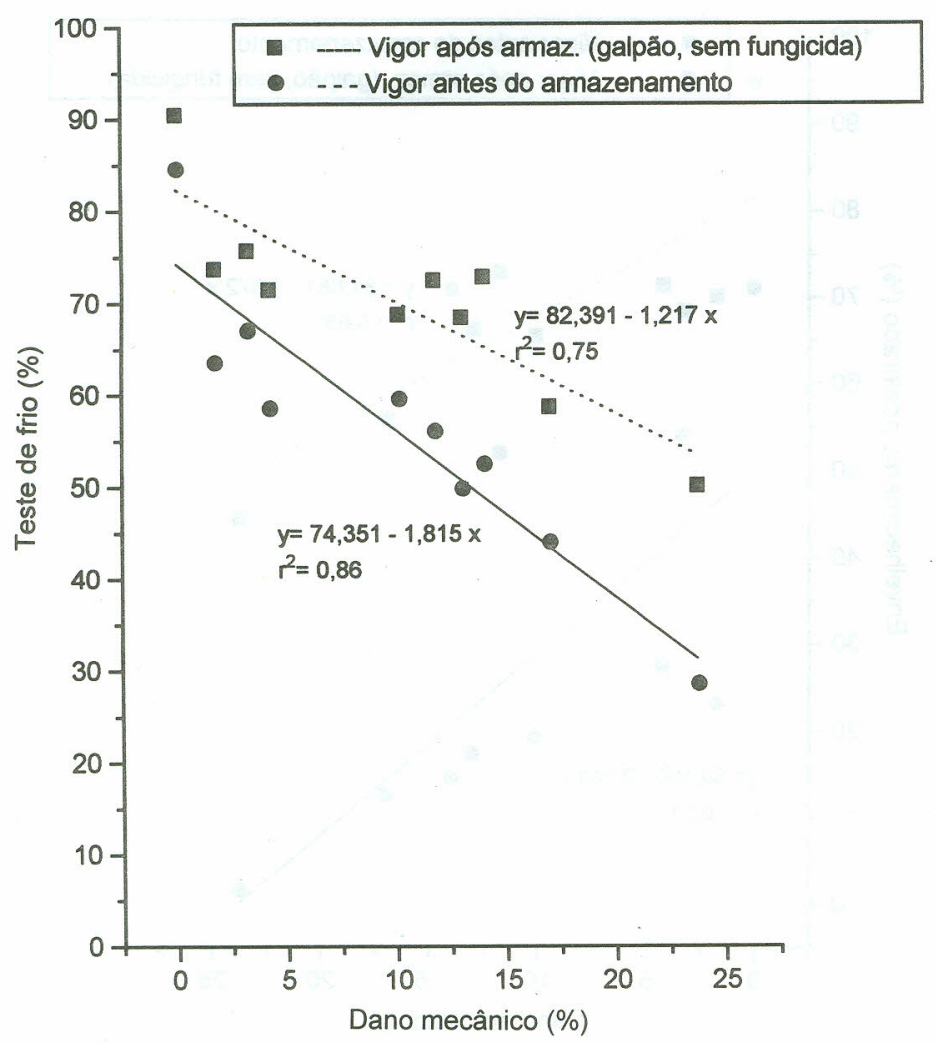

FIG. 5. Efeito do dano mecânico no vigor (teste de frio) de sementes de sorgo, sem fungicida, antes e após armazenamento em galpão. Sete Lagoas - MG, 1996.

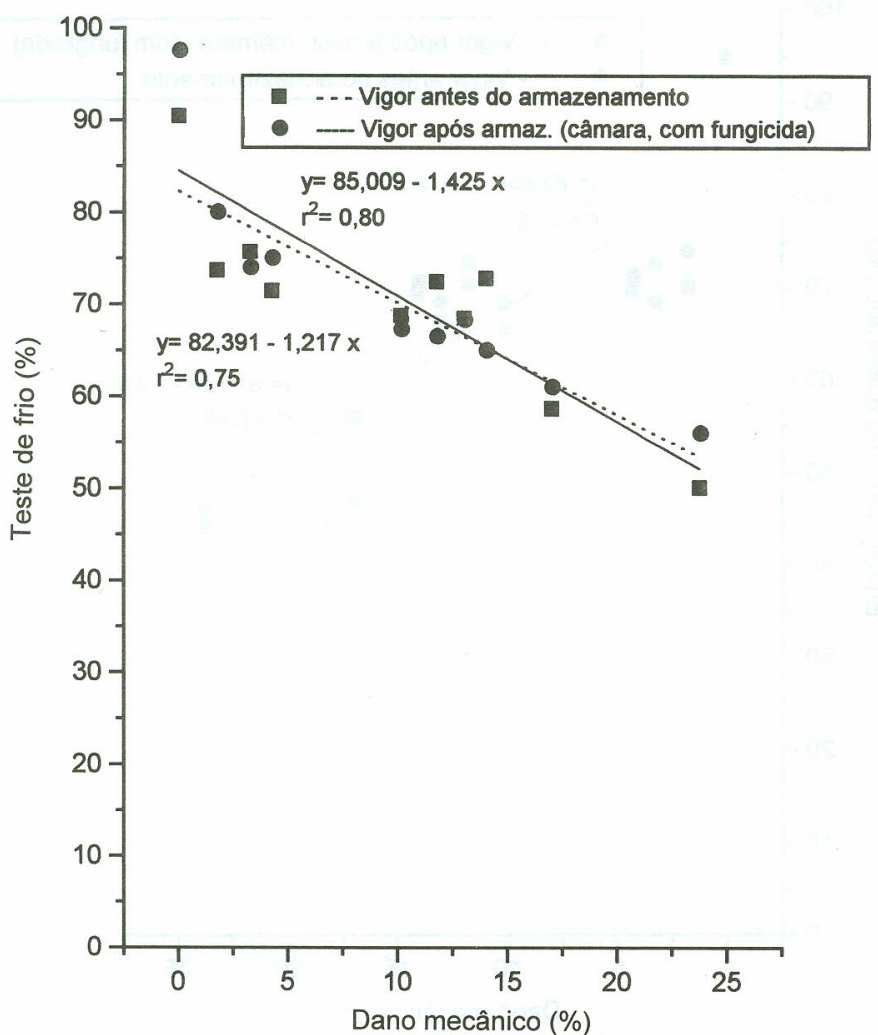

FIG. 6. Efeito do dano mecânico no vigor (teste de frio) de sementes de sorgo, com fungicida, antes e após armazenamento em câmara fria. Sete Lagoas - MG, 1996. mesmo sem dano, as sementes foram afetadas pelo efeito do armazenamento com um decréscimo de aproximadamente $8 \%$ na germinação. Esse decréscimo foi mais acentuado em sementes com dano mecânico. Observa-se que para $23 \%$ de dano as sementes apresentaram germinação em torno de $42 \%$. Isto significa um decréscimo estimado de $17 \%$ de germinação em relação ao lote com mesmo dano, mas antes do armazenamento.

No ambiente câmara fria, com fungicida (Fig. 2) observase que as sementes de sorgo com $23 \%$ de dano, apresentaram germinação estimada de $51 \%$ após o armazenamento. Neste caso, houve um decréscimo estimado de $8 \%$ na germinação em lotes com mesmo grau de dano mecânico.

Na Figura 3, observa-se que as sementes antes do armazenamento apresentaram vigor estimado pelo teste de envelhecimento acelerado, variando de, aproximadamente, $82 \%$, na ausência de dano mecânico a $50 \%$ com $23 \%$ de dano, ou seja, $1,4 \%$ de decréscimo no vigor para cada $1 \%$ de dano. Após seis meses de armazenamento galpão e sementes sem fungicida, o vigor estimado caiu significantemente de $50 \%$ para $2 \%$ no lote de sementes com $23 \%$ de dano mecânico.

Pelos resultados do teste de envelhecimento acelerado (Tabela 2) ficou evidente a ação benéfica do tratamento com fungicida $(\mathrm{ACF})$, proporcionando melhores resultados que a conservação em câmara com sementes sem fungicida (CFSF). As sementes armazenadas em câmara fria e tratadas com fungicida (CFCF) não foram afetadas pelo armazenamento. $\mathrm{O}$ decréscimo observado no vigor, pelo envelhecimento acelerado, nesse ambiente foi de $95 \%$, para sementes sem dano, e de $46 \%$ em sementes com, aproximadamente, $23 \%$ de dano. Estes percentuais não diferiram significativamente daqueles obtidos na avaliação inicial das sementes.

No ambiente com melhores condições de armazenamento (CFCF: câmara fria, com fungicida) observa-se que as sementes de sorgo com $23 \%$ de dano, o vigor estimado pelo teste de envelhecimento acelerado foi de $46 \%$ após o armazenamento. Neste caso, houve um decréscimo estimado de $3 \%$ no envelhecimento acelerado em lotes com mesmo nível de dano mecânico (Fig. 4). Observa-se nesta figura que, para a maioria dos níveis de dano, não houve diferença estatística entre os resultados apresentados antes e depois de armazenamento em CFCF (Tabela 2).

O mesmo aconteceu com os resultados do teste de frio (Tabela 3, Figuras 5 e 6). Observa-se que as sementes, antes do armazenamento, apresentaram dados estimados pelo teste de frio variando de $82 \%$, na ausência de dano mecânico, a 54\%, com $23 \%$ de dano, ou seja, $1,2 \%$ de decréscimo no vigor para cada $1 \%$ de dano. Após seis meses de armazenamento em galpão, sem tratamento com fungicida (ASF), as sementes, na ausência de danos, apresentaram vigor estimado em torno de $74 \%$; ou seja, mesmo sem dano, as sementes foram afetadas pelas condições de armazenamento com um decréscimo de aproximada- 
mente $8 \%$ no vigor. $O$ decréscimo estimado foi mais acentuado quando as sementes foram danificadas. Observa-se que para $23 \%$ de dano as sementes apresentaram vigor estimado em torno de $54 \%$. Isto significa um decréscimo estimado de $22 \%$ no vigor em relação ao lote com mesmo dano na avaliação inicial das sementes.

Já na Figura 6, verifica-se um decréscimo de vigor em torno de $2 \%$ em sementes com diferentes níveis de dano, armazenadas em câmara fria e tratadas com fungicida (CFCF).

Verificou-se que, apesar da germinação imediata das sementes não ter sido afetada pelos vários níveis de dano, o vigor foi significantemente afetado, principalmente após o armazena-mento, conforme também relatado em trabalhos de Gomez (1971), Petrini et al.(1988) e Andrade et al. (1994). Esses trabalhos salientam a sensibilidade das sementes de sorgo em relação às condições de estresse como o teste de envelhecimento acelerado e teste de frio.

Admitindo-se que $70 \%$ seja o limite mínimo aceitável de germinação, verifica-se que as sementes podem ser armazenadas no ASF desde que tenham, no máximo, em torno de $3 \%$ de dano mecânico; no ACF, $10 \%$; no CFSF, $12 \%$ e no CFCF, até $14 \%$ de dano mecânico (Tabela 1).

Já pelo teste de frio, verificou-se que o armazenamento em câmara fria superou o efetuado em condições ambientais, mesmo em sementes tratadas com fungicida (Tabela 3). Nos ambientes ASF, ACF e CFSF, o vigor das sementes de sorgo também apresentou decréscimo significativo pelo teste de frio em decorrência do dano mecânico das sementes. Considerando-se os dois ambientes mais contrastantes (ASF: galpão e sem fungicida; $\mathrm{CFCF}$ : câmara fria e com fungicida) observou-se que o vigor caiu de $84,5 \%$, em sementes sem dano, para $28,5 \%$, quando em sementes com $23 \%$ de dano aproximadamente no ASF (ASF). Estes percentuais, em geral, foram significativamente inferiores àqueles observados nas análises iniciais. Já no CFCF, o vigor caiu de $97,5 \%$, em sementes sem dano, para $56,0 \%$ com $23 \%$ de dano, aproximadamente. Os percentuais observados nos diferentes níveis de dano não diferiram daqueles obtidos em sementes não armazenadas, ou seja, no caso do teste de frio não se verificou nenhum efeito negativo do armazenamento nas sementes tratadas com fungicida armazenadas em câmara fria (Tabela 3).

$O$ índice de velocidade de emergência (IVE) e a população inicial de plantas de sorgo apresentaram comportamento diferenciado dos demais testes de vigor. Não houve diferenças significativas entre os ambientes e os níveis de dano pelo teste F a $5 \%$ de probabilidade para os dados de IVE e população inicial de plantas de sorgo, por isso não foram mostrados. Mesmo assim, em ambos os testes de vigor, os dados indicaram que os melhores ambientes foram, em forma decrescente, CFCF, ACF, CFSF e ASF, evidenciando que o tratamento fungicida foi melhor para a conservação da qualidade fisiológica das se- mentes de sorgo do que o armazenamento de sementes em câmara fria.

Resultados semelhantes de redução da qualidade fisiológica das sementes após sofrerem injúrias, foram encontrados por Borba et al. (1994) estudando o efeito da debulha mecânica em milho. Eles verificaram redução inversamente proporcional da germinação e do vigor em sementes de lotes com diferentes porcentagens de danos mecânicos antes e após seis meses de armazenamento.

Os dados encontrados em relação ao efeito do fungicida sobre a germinação estão em concordância com aqueles descritos por Enayathullah \& Mariappan (1990). No presente estudo as sementes armazenadas e tratadas com Thiram + Vitavax conservaram melhor a qualidade fisiológica em relação àquelas não tratadas. Sementes de sorgo tratadas com fungicida antes do armazenamento conservaram o seu poder germinativo e também o seu vigor. $\mathrm{O}$ mesmo foi encontrado por Medina et al. (1995) em sementes de amendoim armazenadas por períodos prolongados.

Os testes de germinação, envelhecimento acelerado e frio em sementes de sorgo armazenadas por seis meses nas diversas condições deste trabalho foram os mais eficientes na detecção do efeito latente dos diferentes níveis de dano mecânico na qualidade de sementes de sorgo, em relação ao IVE e população inicial.

\section{CONCLUSÕES}

- Os níveis de dano mecânico causaram redução na qualidade fisiológica das sementes de sorgo armazenadas por seis meses;

- sementes de sorgo tratadas com fungicida e armazenadas em câmara fria apresentaram melhor conservação do vigor quando comparadas com aquelas armazenadas nos outros ambientes.

\section{REFERÊNCIAS}

ANDRADE, R.V.de; MANTOVANI, E.C.; OLIVEIRA, A.C.de; FELDMANN, R.O. \& AZEVEDO, J.T. Efeito da colheita mecânica na qualidade fisiológica de sementes de sorgo (Sorghum bicolor (L.) Moench.). Revista Brasileira de Sementes, Brasília. v.18, n.2, p.156-159.1996.

ANDRADE, R.V.de; AZEVEDO, J.T.; BORBA, C.da S. \& OLIVEIRA, A.C.de. Teste de vigor em sementes de sorgo para predizer o armazenamento. Revista Brasileira de Sementes, Brasília. v.16, n.1, p.102-106. 1994.

ASWATHAIAH, B.; PRASAD, S.R.; REDDY, A.S. \& JAGADISH, G.V.Loss of viability and vigour under variable storage conditions in CSH-9 hybrid sorghum seeds. Cur. Research Univ. of Agr. Sc. Bangalore, Bangalore. v.18, n.6, p.79-80. 1989. 
BORBA, C.S.; ANDRADE, R.V.de; AZEVEDO, J.T.de \& OLIVEIRA, A.C.de. Efeito da debulha mecânica na qualidade de sementes de milho (Zea mays L.). Revista Brasileira de Sementes, Brasília. v.16, n.1, p.68-70. 1994.

BRASIL. Ministério da Agricultura e da Reforma Agrária. Regras para análise de sementes. Brasília: SNDA/DNDV/CLAV, 1992. $365 \mathrm{p}$.

CARBONELL, S.A.M.; KRZYZANOWSKI, F.C.; OLIVEIRA, M.C.N.de \& FONSECA JUNIOR., N.da S. Teor de umidade das sementes de soja e métodos de avaliação do dano mecânico provocado no teste do pêndulo. Pesquisa Agropecuária Brasileira, Brasília. v.28, n.11, p.1277-1285. Nov.1993.

CHOWDHURY, M.H. Avaliação de danos mecânicos em milho e sorgo. Procedimento. s.l.: EMBRAPA/CNPMS, 1977.27p. (Tradução e Adaptação).

CÍCERO, S.M. \& VIEIRA, R.D. Teste de frio. In: VIEIRA, R.D. \& CARVALHO, N.M. (ed.) Testes de vigor em sementes. Jaboticabal: FUNEP, 1994. p.151-164.

ENAYATHULLAH SHAH, S. \& MARIAPPAN, V. Effect of seed dressing fungicides on the storage and viability of sorghum seeds. Madras Agric. J., Madras. v.77, n.7 e 8, p.278-280. 1990.

GARCIA, A. \& LASA, J.M. Seed vigour tests for predicting field emergence of grain sorghum under severe conditions. Investigacione Agraria: Producion y Protecion Vegetales, Madri. v.6, n.1, p.5-16. 1991.

GOMEZ, F.M. Influence of mechanical damage on corn seed quality. Mississippi: Universidade do Mississippi. 1971. 49p. (Tese Mestrado).
MARCOS FILHO, J. Teste de envelhecimento acelerado. In: VIEIRA, R.D. \& CARVALHO, N.M (ed.) Testes de vigor em sementes. Jaboticabal: FLNEP, 1994. p.133-149.

MEDINA P.F.; RAZERA, L.F. \& ROSSETTO, C.J. Armazenamento de sementes de amendoim tratadas com inseticidas e fungicida. Revista Brasileira de Sementes, Brasília. v.17, n.2, p.236-242. 1995.

MEHTA, P.M. \& PATEL, B.V. Effect of storage periods and temperatures on micronutrient content and germination in jowar (Sorghum vulgare L.) J- 35 seeds. Advances in Plant Sciences, Oxford. v.3, n.2, p.228-235. 1990.

PETRINI, J.A.; FERNANDEZ, D. \& ZONTA, E.P. Testes de vigor para predizer a emergência de sorgo. Pesquisa Agropecuária Brasileira, Brasília. v.23, n.6, p.593-598. Jun. 1988.

POPINIGIS, F. Fisiologia de sementes. Brasília: AGIPLAN. 1977. 289 p.

SILVEIRA, J.F.da. Efeitos da debulha mecânica sobre germinação, vigor e produção de cultivares de milho (Zea mays L.). Piracicaba: ESALQ, 1974. 47p. (Tese Mestrado).

TENG, Y.T. The effect of storage conditions on the viability, vigour and storability of maize, sorghum and soybean seeds. Mardi Res. Bulletin, Madri. v.9, n.1, p.24-34. 1981.

VANTOAI, T.T. The influence of storage environments on soybean seed quality. Dissertation Abstracts, Ann. Arbor. v.43, n.10, p.3096. 1983. (Ohio State University). 